\title{
Pigeons' memory for empty time intervals marked by visual or auditory stimuli
}

\author{
ANGELO SANTI, LORI ROSS, ROMINA COPPA, and JAMES COYLE \\ Wilfrid Laurier University, Waterloo, Ontario, Canada
}

\begin{abstract}
In Experiment 1, pigeons were trained to discriminate the duration ( 2 or 8 sec) of an empty interval separated by two $1325-\mathrm{Hz}$ tone markers by responding to red and green comparison stimuli. During delay testing, a choose-short bias occurred at $1 \mathrm{sec}$, but a robust choose-long bias occurred at $9 \mathrm{sec}$. Responding in the absence of tone markers indicated that the pigeons were attending to the markers and not simply timing the total trial duration. The birds were then trained to match short (2-sec) or long (8-sec) empty intervals marked by light to blue/yellow comparisons. For both visual and auditory markers, delay testing produced a choose-short bias at $1 \mathrm{sec}$ and a choose-long bias at $9 \mathrm{sec}$. In Experiment 2 , the pigeons were shifted from a fixed to variable intertrial intervals (ITI) within sessions. On trials with tone markers, the duration of both the empty interval and the preceding ITI affected choice responding. On trials with light markers, only the duration of the empty interval influenced choice responding. Subsequent delay testing in the context of variable ITIs replicated the memory biases previously obtained. In Experiment 3, performance was assessed at various delay intervals on trials in which either the first or the second marker was omitted. The data from these omission tests indicated that the first marker initiated timing but that the second marker sometimes initiated the timing of a new interval. Explanations of these effects in terms of the internal clock model of timing are discussed, and a simple quantitative model of the delay interval data is tested.
\end{abstract}

Procedural variables are important in the study of time perception. A comparison of the discrimination of filled intervals and the discrimination of empty intervals has been the focus of some human research (Abel, 1972a, 1972b; Grondin, 1993; Rammsayer \& Lima, 1991), as well as of animal research (Mantanus, 1981). In the empty stimulus condition of the study by Mantanus, a flash of light marked the beginning of the interval, and presentation of the choice keys marked the end of the interval. The filled interval consisted of the continuous presentation of the light. Mantanus found that pigeons were more accurate with filled intervals than with empty intervals. The interpretation of this effect is ambiguous, because of a number of design and general test procedure problems that were recently outlined by Kraemer, Randall, and Brown (1997). In order to address these concerns, Kraemer et al. (1997) conducted a study in which pigeons were trained to discriminate either filled intervals (light present) or empty intervals (light absent). Consistent with the findings of Mantanus, they found that pigeons judged

This research was supported by a grant from the Natural Sciences and Engineering Research Council of Canada (OGPOOD6378). The authors thank Marion Corrick and David Hemsworth for their technical assistance and Melanie Bucking for assisting with some of the data collection. The authors are also very appreciative of the substantial contribution of an anonymous reviewer, who encouraged and guided us in undertaking the quantitative modeling described in Experiment 3. Correspondence concerning this article should be addressed to A. Santi, Department of Psychology, Wilfrid Laurier University, Waterloo, ON N2L 3C5, Canada (e-mail: asanti@mach1.wlu.ca). the duration of a filled interval to be longer than that of an empty interval of equivalent physical duration. However, working memory for the filled and the empty intervals was equivalent, and robust choose-short effects were observed. As the delay interval was increased, accuracy remained high with short-duration samples, but it declined sharply with long-duration samples. These results suggest that signal properties influence duration estimation but not necessarily working memory.

Interestingly, much of the timing literature in rats that has used a temporal bisection procedure has employed a variety of stimulus events, including stimulus presentation (Meck, 1983, 1986, 1991; Morrissey, Wogar, Bradshaw, \& Szabadi, 1993) and stimulus termination (Church, 1980; Church \& Deluty, 1977; Maricq, S. Roberts, \& Church, 1981; Meck \& Church, 1983; S. Roberts \& Holder, 1985), as well as cycles of stimulus onset/offset (Meck \& Church, 1983). Although a direct comparison of these different stimulus presentation methods in the same study has not been reported for rats, many critical features of time perception seem to be unaffected by these differences. For example, the point of subjective equality (PSE) has been at the geometric mean of the two training durations, and the effect of dopaminergic drugs on timing has been very similar, regardless of whether the stimulus consisted of presentation of a light or white noise (Meck, 1983; Morrissey et al., 1993), termination of a light (Church \& Deluty, 1977; Maricq et al., 1981), or cycles of white noise onset/offset (Meck \& Church, 1983).

None of the animal research to date has operationalized an empty interval in the same way as has the human 
research. In human research, a marker indicates the beginning and the end of an empty time interval. An empty intramodal interval is bound by markers from the same sensory mode, whereas an empty intermodal interval is bound by markers from different sensory modes (Grondin, Ivry, Franz, Perreault, \& Metthé, 1996). In this paper, we report a number of experiments in which time perception and temporal memory for empty intramodal intervals in pigeons are examined.

\section{EXPERIMENT 1}

The purpose of the first experiment was to examine pigeons' memory for two empty time intervals marked by either tone or light and to compare these results with those previously obtained with filled intervals of tone or light duration. In humans, duration discrimination for empty and filled intervals is affected by the modality of the markers, as well as by the range of durations tested (Grondin, 1993).

\section{Method}

\section{Subjects}

Six White Carneaux pigeons, maintained at approximately $80 \%$ of their ad-lib weights and housed individually with constant access to grit and water, served as subjects. The colony room was illuminated on a 12:12-h light:dark cycle by fluorescent lights. All of the birds had prior experience in experiments that involved discrimination of visual stimuli, but none had served in experiments involving the timing of light and tone signals.

\section{Apparatus \\ Three touchscreen testing stations located in individual test rooms were used. Each test station consisted of a clear Plexiglas cage ( $30 \mathrm{~cm}$ wide $\times 40 \mathrm{~cm}$ deep $\times 36 \mathrm{~cm}$ high) with a large opening cut into the one end wall, which was constructed of stainless steel. On both the left and the right side walls, adjacent to the stainless steel wall, there were $5.7 \times 5 \mathrm{~cm}$ openings that provided access to a hop- per filled with mixed grain (Coulbourn Model E14-10). A color SuperVGA monitor (Mitsubishi SD4311C) with an attached touch frame (Carrol Touch Inc., Frame 8100-9583-01, Card 8200-3224- 01) was placed against the opening in the stainless steel wall. An IBM- compatible microcomputer located in the same room controlled stimulus displays, recorded peck location, and operated feeders.}

\section{Procedure}

Each trial consisted of the presentation of two $1325-\mathrm{Hz}$ tone markers of 500 -msec duration, generated through the speaker of a microcomputer located adjacent to the touchscreen testing apparatus. The frequency of the tone was the same as that used in several previous studies on the timing of filled tone intervals in pigeons (Cheng \& W. A. Roberts, 1989; W. A. Roberts, Cheng, \& Cohen, 1989; Santi, Stanford, \& Coyle, 1998). The intensity of the tone was $68 \mathrm{~dB}$ in one room and $60 \mathrm{~dB}$ in the other two rooms (as measured from the interior of the Plexiglas cage with a Radio Shack Digital Sound Level Meter 33-2055). The interval of time between the offset of the first marker and the onset of the second marker was 2 or $8 \mathrm{sec}$. Termination of the second marker was followed immediately by the presentation of the color comparison stimuli (red and green fields). The comparison colors were presented in two rectangular response areas, each measuring approximately $3.4 \mathrm{~cm} \times 3.2 \mathrm{~cm}$ (width $\times$ height), one on the left and one on the right side of the monitor (approximately $15.6 \mathrm{~cm}$ apart, as measured from their in- side edges). Position of the color comparison stimuli was counterbalanced over trials. For 3 birds, a response to the green comparison was correct following a 2-sec interval, and a peck to the red comparison was correct following an 8-sec interval. For the remaining 3 birds, the relationship between the interval duration and the correct comparison stimulus was reversed. A single response to one of the comparison stimuli turned them off and, if correct, provided a $3-\mathrm{sec}$ access to mixed grain randomly presented at either the left or the right hopper opening with a probability of .5 . Incorrect responses to the comparison stimuli produced a 3-sec blackout, followed immediately by re-presentation of the same interval duration and comparison stimulus configuration. A correct response on a correction trial produced a 3-sec access to mixed grain, although only the choice response on the initial (noncorrection) trial was used to calculate matching accuracy. When necessary, supplementary feedings of Purina Pigeon Chow occurred after the experimental sessions and on days on which the birds were not run. Within each block of 4 trials, all combinations of the two interval durations with red and green comparison stimuli on the left and right response areas occurred once. The order of presentation was randomized individually for each bird. All the birds received 120 trials per session. The intertrial interval (ITI) was a constant $10 \mathrm{sec}$ in length.

Delay testing with tone markers. Following 25 sessions of training, delay testing was conducted for 10 sessions. Each test session consisted of 144 trials. For each sample duration, 48 trials occurred at the 0 -sec delay, and 8 trials occurred at each of the other delays $(1,3$, and $9 \mathrm{sec})$. This distribution of delays was used so that the reference memory of durations and their associations with the comparison stimuli established during 0 -sec delay training would remain relatively stable during testing (Spetch \& Wilkie, 1983). There was no illumination in the test chamber during the delay intervals. The correction procedure remained in effect on 0 -sec delay trials but not on trials with delays of 1,3 , or $9 \mathrm{sec}$. All the other parameters were the same as those described previously.

Testing with no tone markers. Following delay testing, the birds received five sessions in which 108 of the 144 trials were baseline trials identical to those that preceded delay testing. On the remaining 36 trials, the tone markers were omitted, and additional time was added to the ITI. That is, on half of these test trials, $3 \mathrm{sec}$ (1-sec markers + 2-sec sample) was added to the ITI, and on the other half, $9 \mathrm{sec}(1-\mathrm{sec}$ markers +8 -sec sample) was added to the ITI. One test trial occurred randomly within each block of 4 trials. On test trials, a response either to the left or to the right response area was reinforced by access to mixed grain with a probability of .5 , regardless of the length of time that was added to the ITI.

Training and delay testing with tone and light markers. Following testing, the birds received training with both tone and light markers. Each trial consisted of the presentation of two markers for $500 \mathrm{msec}$, either two 1325-Hz tone markers or two light markers (a homogeneous gray square, $3.3 \times 3.3 \mathrm{~cm}$, presented in the central area of the monitor approximately $12 \mathrm{~cm}$ from the left and right bezel, as measured to the nearest edge). On one half of the trials, the tone markers bounded an interval of either 2 or $8 \mathrm{sec}$. On the remaining trials, the light markers bounded intervals of either 2 or $8 \mathrm{sec}$. Red and green comparisons were presented after intervals marked by the tone, and blue and yellow comparisons were presented after intervals marked by the light. The response contingencies following tone markers were the same as they had been previously. If red had previously been correct following the 2-sec interval marked by the tone, yellow was correct following the 2-sec interval marked by the light. If green had previously been correct following the 2-sec interval marked by the tone, blue was correct following the 2-sec interval marked by the light. Within each block of 8 trials, all combinations of the four sample stimuli (two marker modalities $X$ two durations) and the two comparison stimulus configurations occurred once. The order of presentation was randomized individually for each bird. All the birds received 144 trials per session. All 
the other parameters were the same as those described previously. Each bird received 20 sessions of training.

Each delay testing session consisted of 144 trials. Twenty-four trials for each of the four sample stimuli occurred at the 0-sec delay, and 4 trials for each sample occurred at each of the other delays (1, 3 , and $9 \mathrm{sec}$ ). All the other parameters of delay testing were the same as those described previously. Each bird received 15 sessions of delay testing.

In all the statistical analyses reported in this article, the rejection region was $p<.05$.

\section{Results and Discussion}

The mean percentage of correct matching accuracy during the initial delay tests with tone markers is shown in Figure 1. Accuracy dropped much more on short sample trials than on long sample trials as the delay interval increased. An analysis of variance (ANOVA) conducted on these data indicated a significant main effect for delay $[F(3,15)=18.31]$ and a sample duration $\times$ delay interaction $[F(3,15)=25.42]$. On short sample trials, increasing the delay significantly reduced accuracy $[F(3,15)=$ 33.00]. However, on long sample trials, accuracy initially declined between delays of 0 and $1 \mathrm{sec}$ and then increased at longer delays $[F(3,15)=4.14]$. The choose-short response bias at the 1-sec delay was not statistically significant. At the 9-sec delay, accuracy was significantly greater on long sample trials than on short sample trials $[F(1,5)=20.72]$.

These results are similar to those obtained in a previous experiment in our laboratory with filled intervals of tone (Santi, Stanford, \& Coyle, 1998). As was noted in that paper, the choose-long response bias observed during delay testing could have occurred if the birds failed to attend to the tone markers and simply timed the interval from the end of one trial to the presentation of comparison stimuli on the next trial (i.e., total duration of the trial). Thus, the shorter interval would have been approximately $13 \mathrm{sec}(10$-sec ITI +1 -sec markers +2 -sec sample), and the longer interval $19 \mathrm{sec}$. A great deal of evidence indicates that the PSE between two intervals is at the geometric mean (Church \& Deluty, 1977; Fetterman \& Killeen, 1992; Stubbs, 1968, 1976). If the intervals are 13 and $19 \mathrm{sec}$, the PSE would be expected to be approximately $15.7 \mathrm{sec}$. When a 2 -sec sample was presented, the birds were $58 \%$ correct (close to indifferent between responding short and responding long) following a 3-sec delay. This would be consistent with an internal clock reading approximately equivalent to the PSE on trials consisting of a 10-sec ITI + 1-sec markers + 2 -sec sample $+3-\mathrm{sec}$ delay $=16 \mathrm{sec}$, suggesting that the birds may have been timing two intervals, a shorter one of $13 \mathrm{sec}$ and a longer one of $19 \mathrm{sec}$ (i.e., not timing the interval marked by the two tones at all).

This interpretation was tested by presenting the birds with trials in which the tone markers were omitted but with an interval of time equivalent to the short or the long empty interval plus marker duration added to the ITI (i.e., 3 or $9 \mathrm{sec}$ ). If performance is not disrupted by the absence of the tone markers, this would support the notion that the birds are simply timing the total duration of the trial. On the other hand, if performance is disrupted, the birds are attending to the tone markers and not simply timing the total duration of a trial.

The mean percentage for correct choice during testing is shown in Figure 2. The interaction between sample duration (short vs. long) and trial type (tone markers vs. no tone markers) was statistically significant $[F(1,5)=23.21]$. On baseline trials, when the tone markers were presented, accuracy was above $70 \%$ correct, and there was no difference in accuracy for short and long duration signals $(F<2)$. However, when the tone markers were omitted,

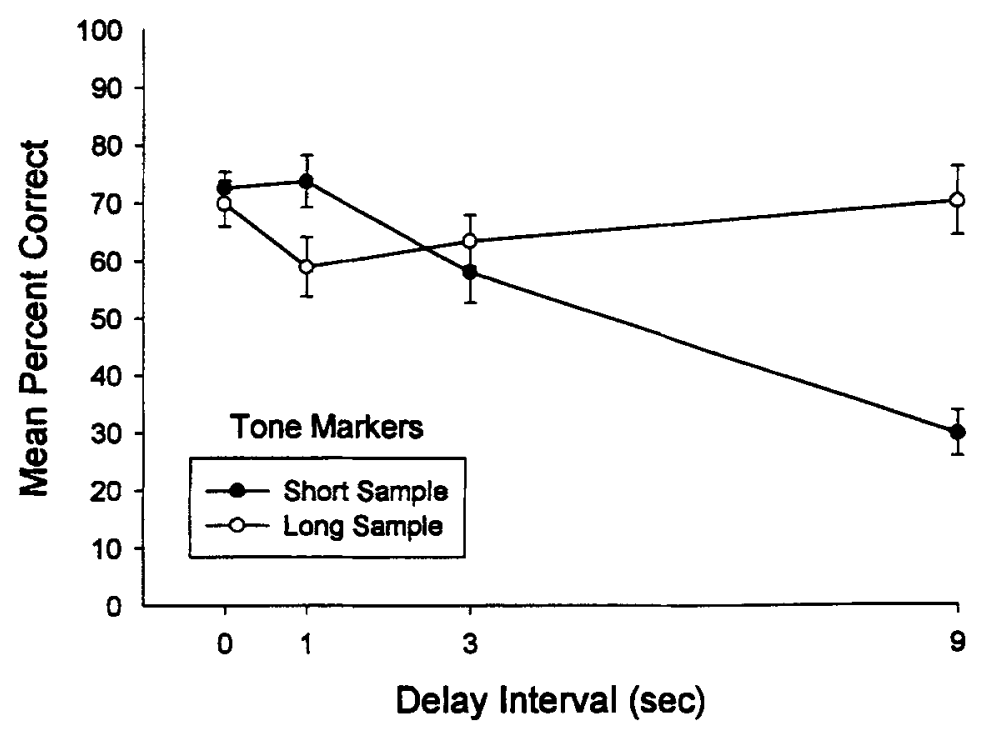

Figure 1. Mean percentage of correct responses during delay testing in Experiment 1 for short and long empty intervals marked by tone. Error bars represent the standard error of the mean. 


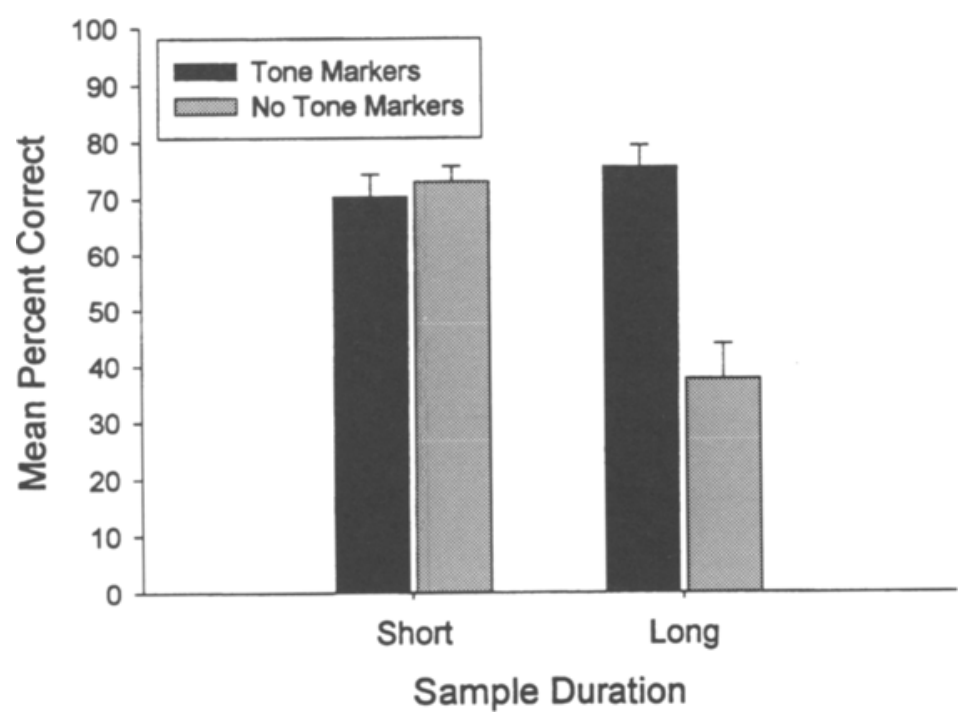

Figure 2. Mean percentage of correct responses during trials in which the tone markers were presented and those in which the tone markers were omitted in Experiment 1. Error bars represent the standard error of the mean.

accuracy was significantly lower on long duration trials than on short duration trials $[F(1,5)=55.99]$. Consequently, the choose-long bias obtained in the previous delay test cannot be explained by claiming that the birds were timing the total trial duration and not attending to the tone markers. Pigeons trained to respond to empty intervals signaled by tone show choose-long biases during delay testing, and this bias is not due to a failure to attend to the tone.

The mean percentages of correct matching accuracy during the delay tests with both tone and light markers are shown in Figure 3. For both tone and light marker trials, a choose-short bias appeared at the 1-sec delay, and a large choose-long bias developed as the delay increased. Accuracy dropped much more on short sample trials than on long sample trials as the delay interval increased. An ANOVA conducted on these data indicated significant main effects for sample duration $[F(1,5)=13.19]$ and for delay $[F(3,15)=59.26]$, as well as significant marker modality $\times$ delay $[F(3,15)=7.73]$ and sample duration $\times$ delay $[F(3,15)=46.82]$ interactions. The marker modality $X$ delay interaction was due to significantly higher accuracy when the markers were lights than when they were tones, but only at the 0 -sec delay $[F(1,5)=$ 15.67]. At delays greater than 0 sec, there were no significant differences in accuracy between trials with light markers and those with tone markers. An analysis of the sample duration $\times$ delay interaction indicated that, at the 0 -sec delay, there was no difference in accuracy between short and long sample durations $(F<1)$. However, at the 1 -sec delay, accuracy was higher on short sample trials than on long sample trials $[F(1,5)=7.29]$. At the 3 -sec delay, there was no significant difference in accuracy between the two sample durations. At the 9-sec delay, ac- curacy on long sample trials was considerably higher than that on short sample trials $[F(1,5)=180.61]$. The shape of the delay functions not only replicates the chooselong bias at the longest delay observed earlier, but also the initial drop in accuracy on long sample trials, relative to short sample trials, between the 0 -sec and the 1-sec delay.

Tests of pigeons' memory for event duration consisting of a filled interval of light typically result in chooseshort effects. The present study, along with Santi, Stanford, and Coyle (1998), demonstrates that a filled interval of tone or an empty interval signaled by either tone or light gives rise to choose-long errors at long delay intervals. These findings are somewhat different from those recently reported by Kraemer et al. (1997), in which choose-short effects occurred when memory for empty intervals was tested. In their study, the empty interval was produced by turning off a houselight that was otherwise always present. It seems that the method used to create an empty interval has a significant impact on the nature of the response biases observed when memory for that interval is tested. The method used by Kraemer et al. (1997) may allow for better control of the internal clock by providing a less ambiguous signal of when timing should stop. In their study, when the empty interval ends, the houselight is turned on and remains on during the delay interval. The delay interval provides a context (houselight on) during which the animal would normally not be timing. In the present study, the end of the empty interval is marked by the brief presentation of the tone or the light. However, the subsequent delay interval is similar to an empty interval that the animal would normally time, and it is also similar to the ITI (see Zentall, 1997, for a discussion of instructional ambiguity and animal memory). Consequently, it is possible that, in our study, 

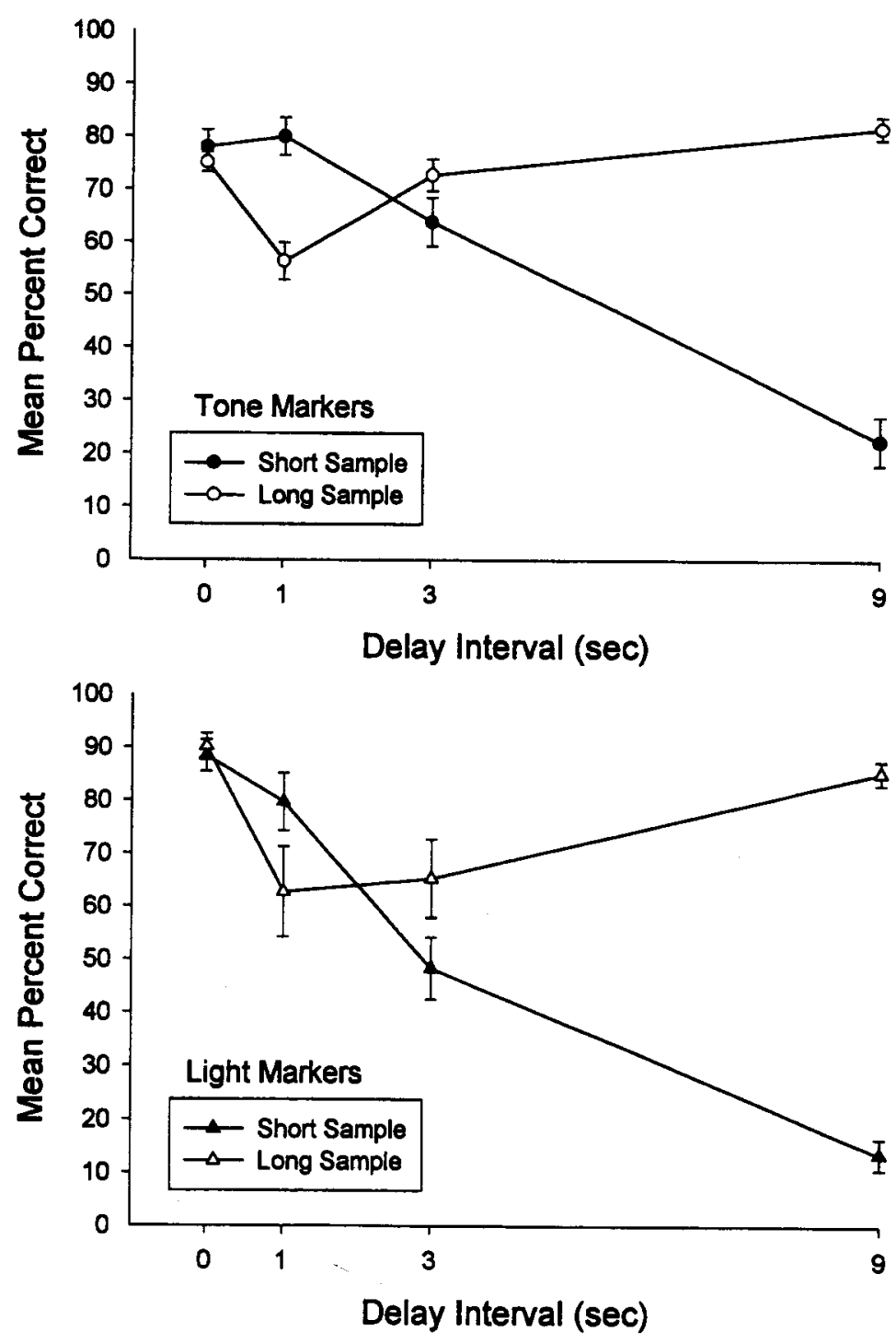

Figure 3. Delay testing data for short and long empty intervals in Experiment 1 as a function of the modality of the markers: tone in the top panel and light in the bottom panel. Error bars represent the standard error of the mean.

the pigeons continued to time during the delay interval because the presentation of the comparison stimuli rather than the second marker turned off the clock. Further consideration of these issues will follow the next experiment.

\section{EXPERIMENT 2}

Spetch and Rusak $(1989,1992 \mathrm{a}, 1992 \mathrm{~b})$ have presented evidence that both perception and memory of event duration are altered by changes in the temporal context within which the event occurs. They have demonstrated that the tendency to respond with a particular bias (e.g., short choices) is altered not just by variation in the time interval after the event (delay), but also by the time in- terval before the event (ITI). Trials preceded by a shorterthan-normal ITI promoted a choose-long response, whereas trials preceded by a longer-than-normal ITI promoted a choose-short response. In addition, the chooseshort effect was larger when delays were varied in the context of a short ITI than in the context of a longer ITI. The previous experiment and the study by Santi, Stanford, and Coyle (1998) have shown that the nature of the response biases produced by manipulation of the delay interval depends on the modality of the signal and choice cues. The present experiment examined whether variations in the ITI would also differentially alter response biases as a function of the modality of the marker. The group of pigeons trained to respond to empty time inter- 
vals in Experiment 1 was shifted from a fixed ITI to variable ITIs within sessions, and memory functions were reassessed with variable ITIs.

\section{Method}

\section{Subjects and Apparatus}

The subjects and apparatus were the same as those used in Experiment 1.

\section{Procedure}

The birds were given 4 sessions of baseline training, consisting of 144 trials with a fixed ITI of $10 \mathrm{sec}$. They were then given 40 sessions of training in which the duration of the ITI varied within ses- sions $(4,8,16$, or $32 \mathrm{sec})$. Each session consisted of 160 trials (20 tone and 20 light trials following each ITI duration). All the other parameters, except for the ITI, were the same as those previously described (including the use of the correction procedure). Following the training with variable ITIs, all the birds were given 15 sessions of testing at delays of $0,1,3$, and $9 \mathrm{sec}$. The ITI continued to vary within sessions, but all the other aspects of delay testing sessions were the same as those described for Experiment 1. Each delay testing session consisted of 144 trials.

\section{Results and Discussion}

Figure 4 shows overall accuracy on the last session of training with the fixed ITI of $10 \mathrm{sec}$ and on the first ses-
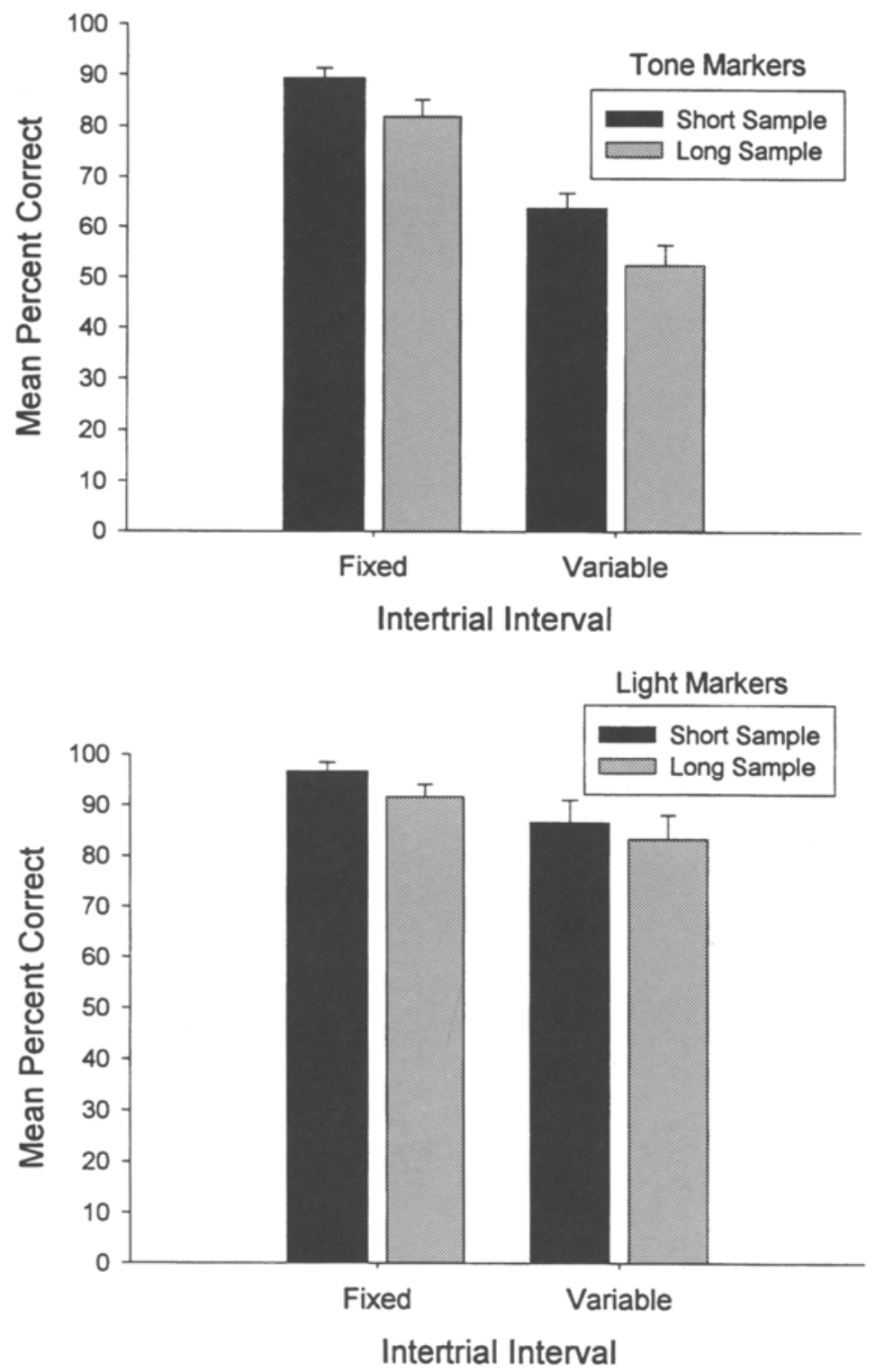

Figure 4. Accuracy on the last session of training with a fixed 10-sec intertrial interval (ITI) and on the first session of training with variable ITIs in Experiment 2 as a function of short and long empty intervals and modality of the markers: tone in the top panel and light in the bottom panel. Error bars represent standard the error of the mean. 
sion of training wiih variabie ITIs. The shift to variable ITIs disrupted accuracy on trials with tone markers, much more than on trials with light markers. An ANOVA conducted on these data indicated significant effects of marker modality $[F(1,5)=19.89]$ and fixed versus variable ITIs $[F(1,5)=68.91]$ and a marker modality $\times$ ITI interaction $[F(1,5)=49.48]$. On the trials with tone markers, accuracy was much lower with the variable duration ITIs than with the fixed duration ITIs $[F(1,5)=141.88]$. The switch to variable ITIs also significantly reduced accuracy on trials with light markers $[F(1,5)=10.82]$, but not to the same extent as on trials with tone markers. As a result, the difference in accuracy between trials with tone markers and those with light markers was greater with the variable ITIs $[F(1,5)=29.04]$ than with the fixed ITIs $[F(1,5)=7.27]$. In addition, accuracy was lower on long sample trials than on short sample trials for the tone markers $[F(1,5)=12.31]$, but not for the light markers $[F(1,5)=5.74]$.

Choice responses during the first session of training with variable ITIs was also examined as a function of the ITI duration that preceded each trial. The mean percent of long responding on trials with tone and light markers is shown in the upper and lower panels of Figure 5. The tendency to respond long on tone trials was strongly affected by the duration of the preceding ITI. The longer
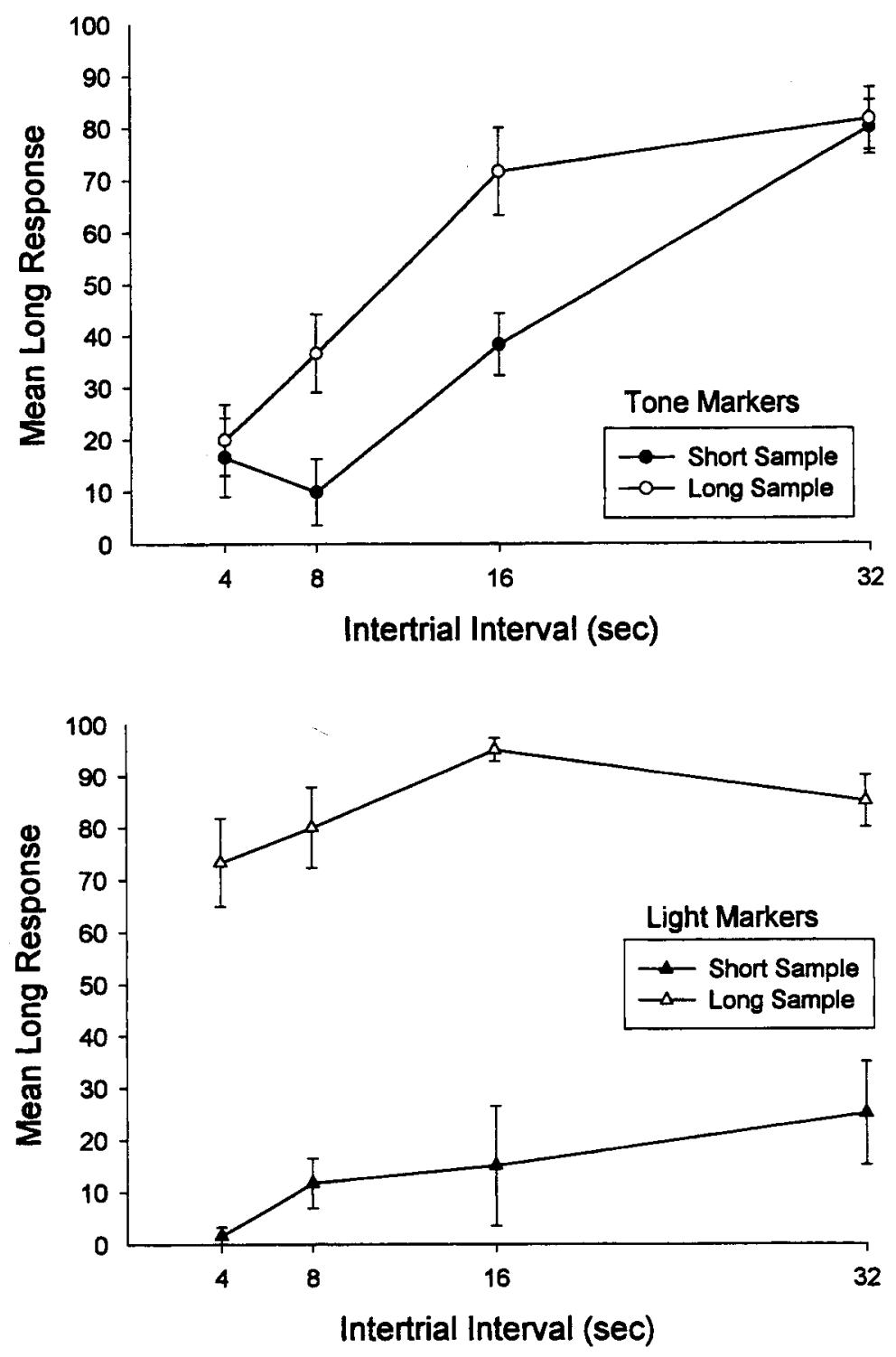

Figure 5. Mean percentage of long responses during the first session of training with variable intertrial intervals (ITIs) in Experiment 2 as a function of the duration of the preceding ITI $(4,8,16$, and $32 \mathrm{sec})$, the duration of the empty interval (short or long), and the modality of the markers: tone in the top panel and light in the bottom panel. Error bars represent the standard error of the mean. 
the preceding ITI, the more likely a pigeon was to classify either the short or the long empty interval as long. However, classification of short and long empty intervals marked by light does not appear to be as strongly affected by the duration of the preceding ITI. An ANOVA of these data indicated significant main effects of ITI $[F(3,15)=$ $27.18]$ and sample duration $[F(1,5)=69.54]$. More importantly, there were significant modality $\times \operatorname{ITI}[F(3,15)=$ 7.94], sample duration $\times$ ITI $[F(3,15)=6.35]$, and modality $\times$ sample duration $[F(1,5)=29.04]$ interactions. Subsequent analyses indicated that, on trials with light markers, the only factor affecting responding was sample duration $[F(1,5)=71.27]$. Neither the ITI effect nor the sample duration $\times$ ITI interaction was statistically significant. However, on trials with tone markers, ITI duration significantly affected long responding, both when the sample was short $[F(3,15)=24.06]$ and when the sample was long $[F(3,15)=17.41]$.

Variable ITIs not only selectively affected responding on tone trials during the 1 st session of the shift, they continued to have an effect even after 35 sessions of training. This is shown in Figure 6, where the data for the last 5 sessions of training with variable ITIs are summarized in terms of the percentage of long responses. It is evident that responding on trials with light markers does not appear to be affected by whether the preceding ITI was 4 ,
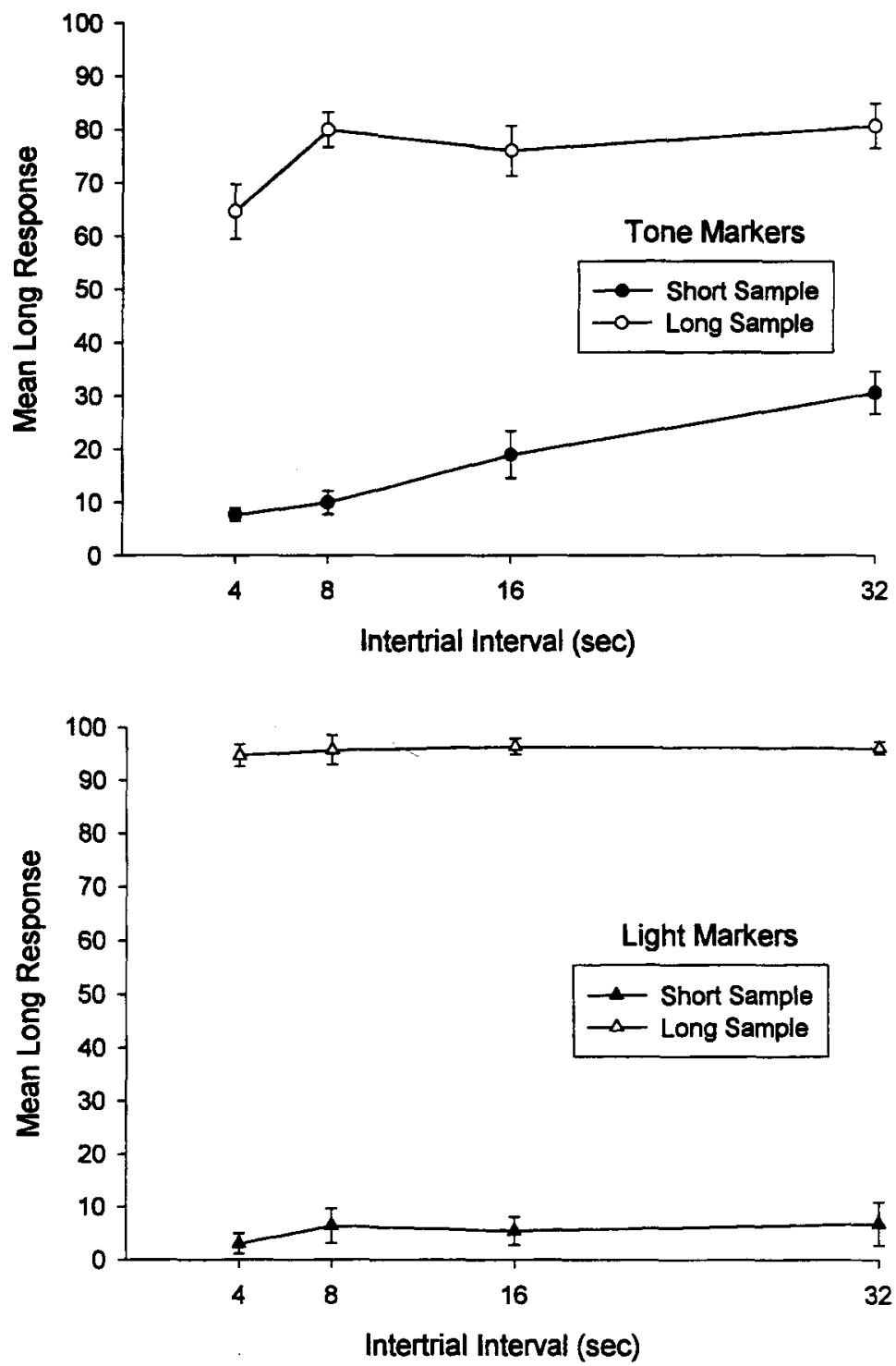

Figure 6. Mean percentage of long responses averaged over the last five sessions of training with variable intertrial intervals (ITIs) in Experiment 2 as a function of the duration of the preceding ITI $(4,8,16$, and $32 \mathrm{sec})$, the duration of the empty interval (short or long), and the modality of the markers: tone in the top panel and light in the bottom panel. Error bars represent the standard error of the mean. 
8,16 , or $32 \mathrm{sec}$. However, the tendency to choose long on trials with tone markers is systematically affected by the duration of the preceding ITI, regardless of the actual duration of the empty interval. An ANOVA of these data indicated significant main effects of ITI $[F(3,15)=$ 30.95], marker modality $[F(1,5)=9.93]$, and sample duration $[F(1,5)=309.83]$. In addition, there was a significant marker modality $\times$ ITI interaction $[F(3,15)=$ $12.42]$ and a marker modality $\times$ sample duration interaction $[F(1,5)=33.34]$. The probability of responding long was significantly affected by the preceding ITI duration on trials marked by the tone $[F(3,15)=25.74]$, but not on trials marked by the light $(F<2)$. The probability of responding long following the long duration sample, in comparison with the short duration sample, was greater on light trials $[F(1,5)=571.53]$ than on tone trials $[F(1,5)=93.33]$.

These data indicate that the absolute duration of an empty interval marked by light controlled choice responding more than did the absolute duration of the empty interval marked by tone. Although the duration of the preceding ITI had no effect on responding when the trial consisted of an empty interval marked by light, it did affect responding when the trial consisted of an empty interval marked by tone. When the interval tested was marked by tones, the longer the preceding ITI, the higher the probability of responding long. This pattern of findings regarding ITI effects and empty intervals marked by tones or lights replicates those observed with filled intervals marked by tones or lights (Santi, Coyle, Coppa, \& Ross,
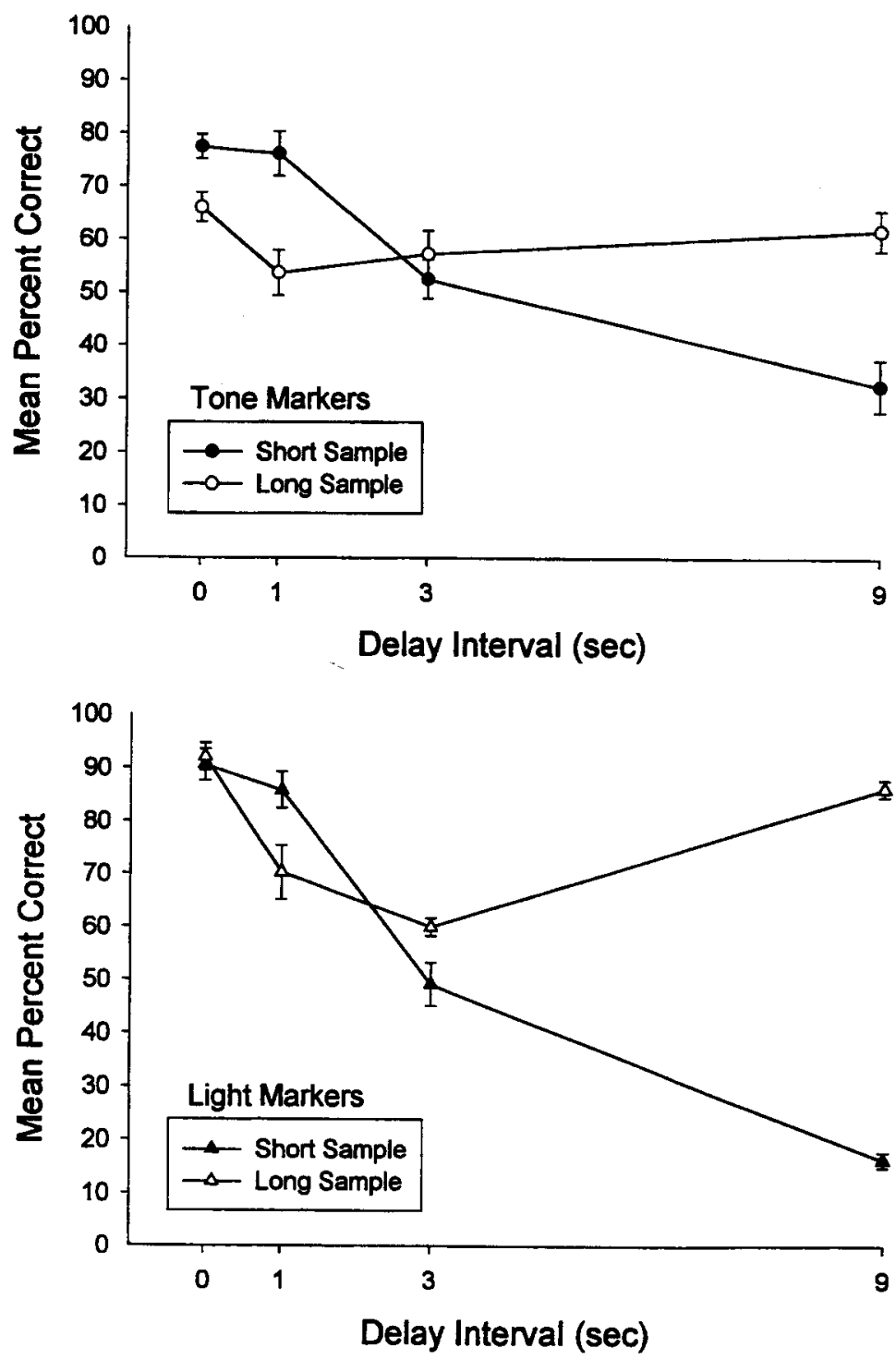

Figure 7. Delay testing data for short and long empty intervals in Experiment 2 as a function of the modality of the marker: tone in the top panel and light in the bottom panel. Error bars represent the standard error of the mean. 
1998). Control by sample duration is greater when lights rather than tones are used either as markers or as signals. In addition, the preceding ITI duration significantly affects responding to filled or empty intervals marked by tone, but not to filled or empty intervals marked by light. Both Meck and Church (1982) and Raslear, Shurtleff, and Simmons (1992) have reported that rats responding in time estimation procedures use both the signal duration and the ITI duration.

The data obtained during delay testing are shown in Figure 7. As in the previous experiment, a small chooseshort bias occurred at the 1 -sec delay, and a large chooselong bias occurred at the longest delay. An ANOVA indicated significant main effects for marker modality $[F(1,5)=27.86]$, delay $[F(3,15)=105.42]$, and sample duration $[F(1,5)=9.83]$. In addition, all of the interactions, including the marker modality $X$ sample duration $\times$ delay interaction $[F(3,15)=7.78]$, were statistically significant. The sample duration $\times$ delay interaction was statistically significant both when the marker modality was tone $[F(3,15)=24.68]$ and when it was light $[F(3,15)=$ 82.03]. On trials with the tone markers, accuracy was greater when the sample was short than when it was long at the 0 - and 1 -sec delays $[F(1,5)=75.05$ and 12.01 , respectively]. There was no difference in accuracy at the 3 -sec delay $(F<1)$, but at the 9-sec delay, accuracy was greater on long sample trials than on short sample trials $[F(1,5)=12.39]$. A similar pattern of results was obtained on trials with the light markers. Accuracy was greater on short sample trials than on long sample trials at the 1-sec delay $[F(1,5)=7.61]$. There was no difference in accuracy at the $3-\mathrm{sec}$ delay $[F(1,5)=5.66]$, but at the 9-sec delay, accuracy was greater on long sample trials than on short sample trials $[F(1,5)=1,765.50]$.

Memory for empty intramodal intervals has features that are quite different from those associated with memory for filled intervals of tone or light. Filled intervals of tone and light give rise to markedly different response biases during delay testing. A choose-short bias occurs when memory for a filled light interval is assessed, whereas a choose-long bias occurs when memory for a filled tone interval is assessed. This difference has been explained in terms of differences in the stimulus that controls termination of timing. Empty intervals marked by tones or lights produce very similar response biases during delay testing: an initial choose-short bias at a 1-sec delay and a large choose-long bias at the longest delay.

\section{EXPERIMENT 3}

In the present study, explanations for the pattern of response biases observed with empty intramodal intervals during delay testing are investigated. One possible explanation is that the pigeons use the first marker to start timing but use the onset of the comparisons to terminate timing. This would give rise to a choose-long effect at long delays, but it would not produce a choose-short ef- fect at the short delay. Another possible explanation is that the pigeons might have been using a counting strategy with the intramodal markers. If they learned to respond on the basis of the number of events that occurred within the previous 3 or $4 \mathrm{sec}$, short empty interval trials would consist of two events, and long empty interval trials would consist of a single event. A choose-long bias during delay testing would then actually be a choose-few bias (see W. A. Roberts, Macuda, \& Brodbeck, 1995). However, like the previous timing explanation, it has difficulty accounting for the response bias that occurs at the short delay. Another explanation of the retention functions, which is more consistent with the data, suggests that, on some proportion of the trials during delay testing, the pigeons might initiate the timing of a new interval when the second marker is presented. On trials in which this occurred, the pigeon's response would be based on the time since the second marker. This would result in a choose-short bias at very short delays and a chooselong bias at long delays.

The purpose of Experiment 3 was to evaluate this explanation of the retention functions obtained with empty intramodal intervals. Performance was assessed at various delay intervals on trials in which either the first marker or the second marker was omitted. On trials in which the second marker is omitted, the birds would be expected to initiate timing from the presentation of the first marker until the presentation of the comparison stimuli. At a delay interval of $0 \mathrm{sec}$, accuracy on trials with an omitted second marker should be similar on short and long sample trials. However, as the delay interval increases, accuracy should show a selective decrease on short sample trials, because timing would continue and the probability of a long response would increase. There should be no evidence of an initial choose-short bias at the 1-sec delay because, without the second marker, there would be no basis for initiating the timing of a new interval.

On trials in which the first marker is omitted, the birds would not be expected to initiate timing until the second marker occurred. Consequently, one would anticipate an initial choose-short bias on omission trials in which the comparison stimuli immediately followed the second marker ( 0 -sec delay). The choose-short bias would be expected to increase at the 1-sec delay, because timing would start from the second marker on these trials and the count duration with a 1 -sec delay would be more similar to that established for the short empty interval on training trials with both markers presented. However, the tendency to respond to the short comparison alternative would decrease at delays much longer than $1 \mathrm{sec}$. At the longest delay of $9 \mathrm{sec}$, a choose-long bias would be expected.

\section{Method}

\section{Subjects and Apparatus}

The subjects and apparatus were the same as those used in Experiments 1 and 2, except for a change in the delivery and intensity 
of the auditory cue. The $1325-\mathrm{Hz}$ tone was generated by a SoundBlaster 16-OEM audiocard and played through stereo speakers (Yamaha YST-M15) located at the left and the right side walls, next to the hopper openings and approximately $14 \mathrm{~cm}$ from the edge of the bezel of the monitor. The intensity of the tone was approximately $85-88 \mathrm{~dB}$.

\section{Procedure}

The birds were given 15 sessions of testing in which the second marker was omitted on some trials, followed by an additional 15 sessions of testing in which the first marker was omitted on some trials. Each testing session consisted of 192 trials, in which 128 trials were regular trials with both markers being presented as previously described (including the use of the correction procedure). On the remaining 64 trials, the second tone or the second light marker was omitted, and a time interval equal in duration to the marker occurred $(500 \mathrm{msec})$. Following this interval, the comparison stimuli were then presented after a delay of $0,1,3$, or $9 \mathrm{sec}$. Each delay was tested equally often on marker omission trials. One marker omission trial occurred randomly within each block of 3 trials. On probe trials, the birds were reinforced for responding to the response area that was correct for the time that had elapsed from the offset of the first marker until the point at which the second marker would have been presented. Following these test sessions, the birds were given additional test sessions in which the first marker was omitted. On these trials, additional time $(2.5$ or $8.5 \mathrm{sec})$ was added to the ITI, and then the second marker was presented, followed by a delay interval of $0,1,3$, or 9 sec. On the omission trials, the birds were reinforced for responding to the response area that would be correct on the basis of the time that had elapsed from the end of the omit-
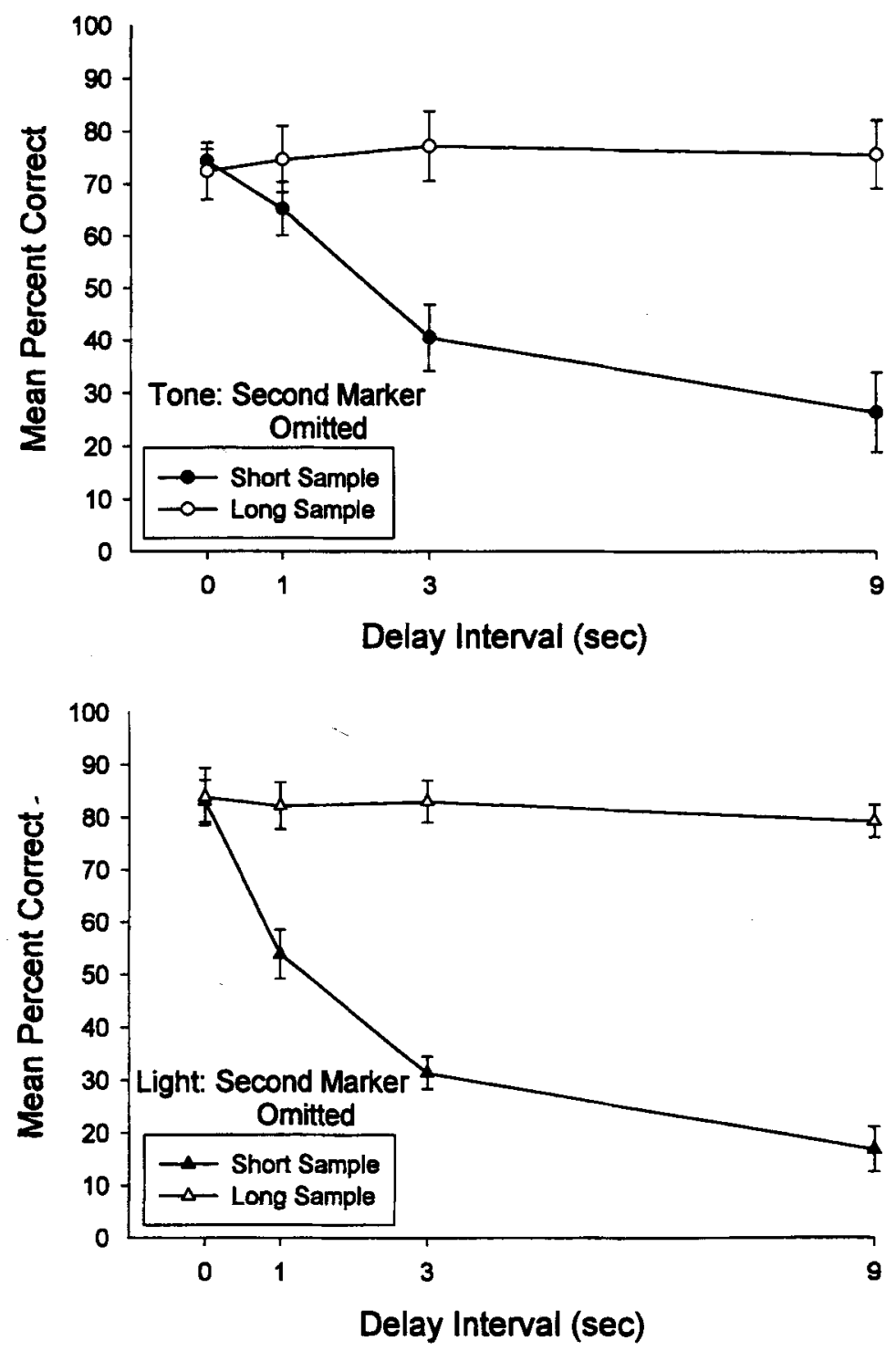

Figure 8. Mean percentage of correct responses on trials in which the second marker was omitted in Experiment 3 as a function of delay from the point at which the second marker would have terminated: tone in the top panel and light in the bottom panel. Error bars represent the standard error of the mean. 
ted marker until the point at which the second marker was presented. Except for the omission of the first marker, these test sessions were conducted in the same fashion as those in which the second marker was omitted.

\section{Results and Discussion}

The data obtained during test sessions in which the second marker was omitted and the delay interval was varied are shown in Figure 8. Accuracy at the 0 -sec delay was equivalent on the short and long sample trials for both the tone and the light. As the delay interval increased, accuracy remained high for the long sample trials, but it decreased rapidly on the short sample trials. An ANOVA indicated significant main effects of delay
$[F(3,15)=28.29]$ and of sample $[F(1,5)=19.55]$, as well as a significant sample $\times$ delay interaction $[F(3,15)=$ 44.69]. Delay significantly reduced accuracy on short sample trials $[F(3,15)=42.54]$, but it had no effect on long sample trials $(F<1)$. At the 0 -sec delay, accuracy was equivalent on short and long sample trials $(F<1)$; however, at the 1-, 3-, and 9-sec delays, accuracy was greater on long sample trials than on short sample trials $[F \mathrm{~s}(1,5)=13.30,21.89$, and 32.02 , respectively $]$. The analysis also revealed a significant modality $x$ delay interaction $[F(3,15)=3.91]$. At the 0 -sec delay, accuracy was higher on light marker trials than on tone marker trials $[F(1,5)=9.67]$. However, at longer delays, there was no significant difference in accuracy between visual and
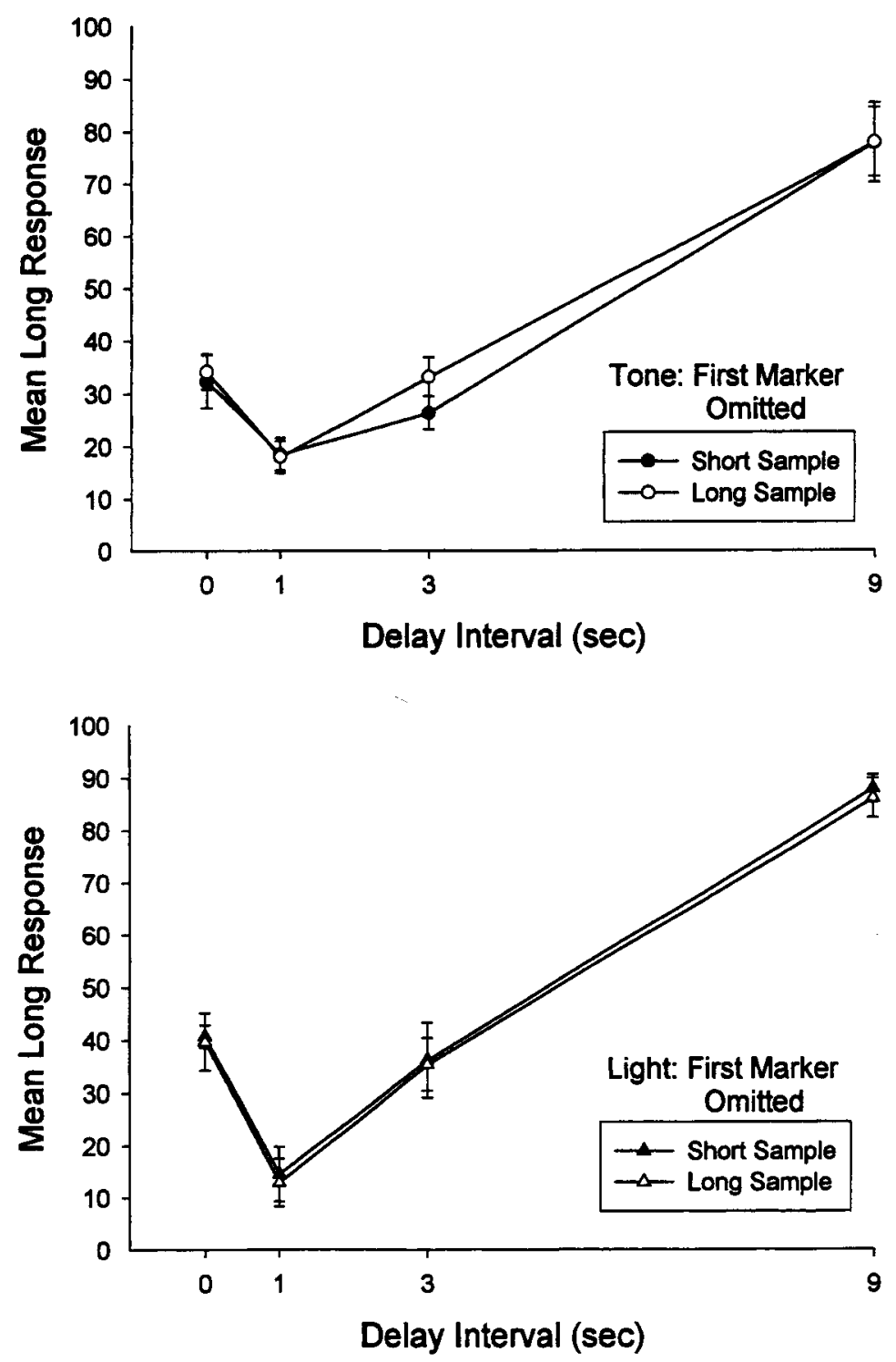

Figure 9. Mean percentage of long response on trials in which the first marker was omitted in Experiment 3 as a function of delay from the termination of the second marker: tone in the top panel and light in the bottom panel. Error bars represent the standard error of the mean. 
auditory markers $(F \mathrm{~s} \leq 1.60)$. These data are consistent with the hypothesis that pigeons initiate timing from the presentation of the first marker until the presentation of the comparison stimuli. The absence of an initial choose-short bias at the 1-sec delay is consistent with the hypothesis that the second marker on regular trials sometimes initiated the timing of a new interval. In the absence of the second marker, no initial choose-short bias was observed.

The data obtained during test sessions in which the first marker was omitted and the delay interval was varied are easiest to understand if they are presented in terms of the probability of a long response rather than percent correct, because there was no basis on which the birds could discriminate short from long sample trials in the absence of the first marker. The data are shown in Figure 9. At the three shortest delay intervals, there was a choose-short response bias (the probability of a long response was below $50 \%$ ), whereas at the longest delay, there was a marked choose-long bias (the probability of a long response was well above $50 \%$ ). Because there was no basis for differential responding on short and long sample trials, these two functions are superimposed on one another. An ANOVA on these data only produced a significant main effect for delay interval $[F(3,15)=$ 59.01]. Additional analyses indicated that both the linear and the quadratic trend across the delay interval were statistically significant $\left[F_{\mathrm{S}}(1,5)=59.94\right.$ and 109.69 , respectively]. Bonferroni multiple comparisons indicated that the probability of a long response was significantly higher at the 9-sec delay than at each of the shorter delays $[t(15)=8.73,12.10$, and 9.49]. In addition, the probability of a long response was significantly lower at the 1-sec delay than at either the 0 -sec or the 3-sec delay $[t(15)=3.97$ and 3.21]. There was no difference in the probability of a long response between the 0 -sec and the 3 -sec delays $(t<1)$. These results are consistent with the idea that, on some proportion of the trials, the birds initiated the timing of a new interval when the second marker occurred. The choose-short bias observed at the 0 -sec delay increased at the 1-sec delay and then decreased at the 3-sec delay. At the 9-sec delay, a choose-long bias was seen.

The data obtained in this experiment can be used to test a simple quantitative model of how pigeons might process the two markers in order to respond accurately at different delay intervals. According to this model, the pigeons time from the first marker to the onset of the comparisons with probability $p$, and they time from the second marker to the onset of the comparisons with probability $1-p$. In addition, it is assumed that the birds never miss both markers. The data obtained from the omission of the second marker and the first marker were weighted in order to provide least-squares estimates of the probability of timing from the first marker or from the second marker such that the best prediction of the delay functions averaged over the data reported in Figures 1, 3, and 7 was obtained. In order to test the model, the data for tone markers and light markers for each individual bird were modeled separately.

The empirical delay function for tone and for light markers averaged over the various delay tests are shown in Figure 10, along with the function predicted by the model obtained by averaging over the predicted functions for each bird. The error bars in the figure, drawn around the empirical data points, are $95 \%$ confidence intervals. As can be seen in Figure 10, this very simple model accounted for the tone marker data quite well. Seven of the eight predicted means do not differ significantly from the empirical means. The one discrepancy was that the predicted accuracy for long sample durations at the 0 -sec delay significantly underpredicted the true level of accuracy. The model did not do as well with the light marker data, particularly at the shorter delays. Here there was significant underprediction of accuracy for both the short and the long sample durations at the 0 -sec delay and for the short sample duration at the 1-sec delay. For the light marker data, accuracy at the 0-sec delay during regular delay testing was somewhat higher than that obtained during probe tests with only the first light marker presented. Consequently, even if the probability of timing from the first maker was set at 1.0 in the model, the result would still have been underprediction of the 0 -sec delay data for light markers. It may be that the absence of the second light marker produced generalization decrement effects that disrupted responding to the comparisons on light marker trials. This was not the case for the tone marker data. Here, the assumption of timing from the first tone marker with probability equal to 1.0 would have provided a very satisfactory prediction of the 0-sec delay test data. The model's underprediction of long sample accuracy at the 0 -sec delay for tone markers occurred because of the weighting of 0 -sec data from trials in which the first tone marker was omitted. These trials were associated with a strong choose-short bias. Additional work is needed to determine whether more complicated models can provide a more satisfactory fit to the data at short delay intervals for both light and tone.

\section{GENERAL DISCUSSION}

Experiment 1 indicated that pigeons can learn to make judgments of empty intervals marked by a tone or a light. When memory for these empty intervals was assessed, a choose-short bias was observed at a delay of $1 \mathrm{sec}$, and a choose-long bias was observed at the longest delay, regardless of whether the empty interval was marked by a tone or a light. In Experiment 2, when tone was used as a marker, both the duration of the empty interval and the ITI duration controlled choice responding. However, when light was used as a marker, only the duration of the empty interval was used to guide choice responding. In Experiment 3, when only the first marker was present, a strong choose-long bias occurred, with no evidence of a choose-short bias at the 1-sec delay. When only the sec- 

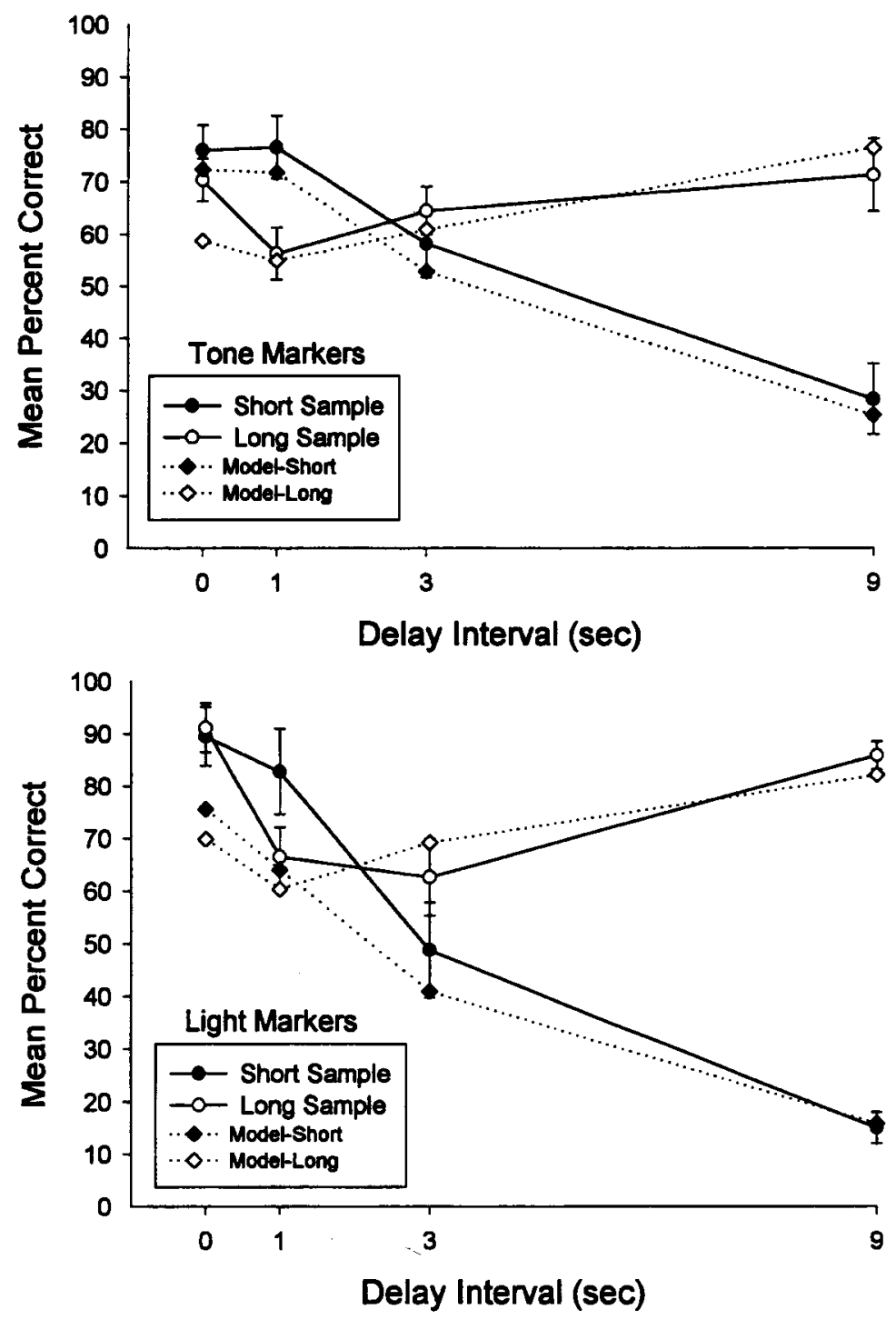

Figure 10. Predictions generated by a simple quantitative model of timing from the first or the second marker for delay interval data obtained for tone markers (Figures 1, 3, and 7) and for light markers (Figures 3 and 7). Error bars represent the $95 \%$ confidence interval.

ond marker was presented, the birds showed a chooseshort bias at the 0 -sec delay, and this bias increased at the 1 -sec delay. At delays longer than $1 \mathrm{sec}$, the birds displayed an increasing probability of responding long.

These findings indicate that pigeons can learn to successfully time empty intramodal intervals, using a procedure for operationalizing an empty interval that is closer to that used in human research (Abel, 1972a, 1972b; Grondin, 1993; Grondin et al., 1996; Rammsayer \& Lima, 1991) than to that which has been used in previous animal work (Kraemer et al., 1997; Mantanus, 1981). Memory for empty intramodal intervals has features that are quite different from those associated with memory for filled intervals of tone or light. Filled intervals of tone and light give rise to markedly different response biases during delay testing. A choose-short bias occurs when memory for a filled light interval is assessed, whereas a chooselong bias occurs when memory for a filled tone interval is assessed. This difference has been explained in terms of differences in the stimulus that controls termination of timing. Empty intervals marked by tones or lights produce very similar response biases during delay testing: an initial choose-short bias at a 1-sec delay and a large choose-long bias at the longest delay. The processes responsible for the change in response biases across the retention interval were studied in Experiment 3. The results were generally consistent with the hypothesis that, on some proportion of the trials, the pigeons initiated the timing of a new interval when the second marker was followed by a delay. On these trials, the pigeon's response 
would be based on the time since the second marker. This would result in a choose-short bias at very short delays and a strong choose-long bias at long delays. A simple quantitative model was tested that used the data from marker omission testing in Experiment 3 to predict the delay test data reported in Figures 1, 3, and 7. The model fit the tone marker data quite well, but it did not provide as good a fit for the light marker data.

Unlike the delay functions, the results concerning the effect of ITI duration on the timing of empty intramodal intervals were very similar to those obtained when the timing of filled intervals of tone or light was studied (Santi, Coyle, et al., 1998). In both cases, the duration of the preceding ITI increased the probability of long responses when comparisons associated with tones were presented. No effect of the ITI on responding was observed on trials in which the comparisons associated with lights were presented. The internal clock model explanation for the effects of ITI duration on filled intervals of tone and light outlined in Santi, Coyle, et al. would appear to extend to empty intervals marked by tone and light. According to this account, the pigeons time both the ITI and the event duration on all trials. Evidence of control by the ITI depends on the relative number of pulse counts generated by the short and long events being timed. The higher the number of pulse counts generated by the event duration itself, relative to that generated by the ITI, the less ITI duration would affect choice responding. Assuming that filled or empty time intervals signaled by lights produce higher pulse counts than those signaled by tones, one would expect less of an effect of ITI on light trials than on tone trials. This assumption would be consistent with the idea of attentional dominance of light over tone stimuli in pigeons (Kraemer \& W. A. Roberts, 1985; W. A. Roberts et al., 1989) or with the idea that more intense or arousing stimuli increase the rate of the pacemaker (Kraemer, Brown, \& Randall, 1995; Penton-Voak, Edwards, Percival, \& Weardon, 1996; Weardon, Edwards, Fakhri, \& Percival, 1998; Wilkie, 1987).

The nature of the ITI effects reported in this paper are similar to those reported in rats (Meck \& Church, 1982; Raslear et al., 1992), but they are different from those previously reported in pigeons by Spetch and Rusak (1989, 1992a, 1992b). In the former case, it appears that animals actually time the ITI as well as the event duration, and this results in a tendency to choose long as the ITI increases. In the later case, it appears that animals do not actively time the ITI but, rather, reset the accumulator during the ITI. Incomplete resetting of accumulated counts can account for some of the Spetch and Rusak results, such as the tendency to choose long when trials are preceded by shorter-than-normal ITIs. One possible factor responsible for these contrasting ITI effects could be the extent to which the signals being timed elicit a strong attentional response. If signals such as tones in pigeons are attended to relatively poorly, other intervals (such as the
ITI) may also be timed and compete for control of responding. Signals such as lights that elicit strong attentional responses may prevent other intervals (such as the ITI) from being timed. Consequently, in studies in which only light signals are used, resetting effects may be observed as the ITI is varied. In studies in which either tone signals alone or both tone and light signals are used, timing effects may be observed as the ITI is varied. However, the detection of this ITI timing effect is only observed for tones in the case of mixed auditory and visual signals, for reasons outlined in the internal clock model explanation provided earlier.

In summary, pigeons can learn to time empty intramodal intervals. Their memory for these intervals produces biases in memory that differ from those associated with filled intervals of tone or light. These memory biases, particularly for intervals marked by tones, appear to be accounted for by a simple model that assumes that the birds usually time from the onset of the first marker but occasionally miss the first marker and time from the onset of the second marker. In addition, it was shown that the timing of empty intervals marked by tones shows a sensitivity to ITI duration similar to that previously shown for filled tone intervals. The timing of filled or empty intervals of visual events does not show the same sensitivity to ITI duration. These differential effects of ITI duration on the timing of visual and auditory events can be understood in terms of the information-processing model of timing.

\section{REFERENCES}

ABEL, S. M. (1972a). Discrimination of temporal gaps. Journal of the Acoustical Society of America, 52, 519-524.

ABEL, S. M. (1972b). Duration discrimination of noise and tone bursts. Journal of the Acoustical Society of America, 51, 1219-1223.

Cheng, K., \& RoberTs, W. A. (1989). Timing multimodal events in pigeons. Journal of the Experimental Analysis of Behavior, 52, 363-376.

ChuRCH, R. M. (1980). Short-term memory for time intervals. Learning \& Motivation, 11, 208-219.

ChuRCh, R. M., \& Deluty, M. Z. (1977). Bisection of temporal intervals. Journal of Experimental Psychology: Animal Behavior Processes, 3, 216-228.

Fetterman, J. G., \& KilleEn, P. R. (1992). Time discrimination in Columbia livia and Homo sapiens. Journal of Experimental Psychology: Animal Behavior Processes, 18, 80-94.

GRONDIN, S. (1993). Duration discrimination of empty and filled intervals marked by auditory and visual signals. Perception \& Psychophysics, 54, 383-394.

Grondin, S., Ivry, R. B., Franz, E., Perreault, L., \& Metthé, L. (1996). Markers' influence on the duration discrimination of intermodal intervals. Perception \& Psychophysics, 58, 424-433.

Kraemer, P. J., Brown, R. W., \& Randall, C. K. (1995). Signal intensity and duration estimation in rats. Behavioural Processes, 34, 265-268.

Kraemer, P. J., Randall, C. K., \& Brown, R. W. (1997).The influence of stimulus attributes on duration matching-to-sample in pigeons. Animal Learning \& Behavior, 25, 148-157.

KRAEMER, P. J., \& RoBERTS, W. A. (1985). Short-term memory for simultaneously presented visual and auditory signals in the pigeon. Journal of Experimental Psychology: Animal Behavior Processes, 11, 137-151. 
Mantanus, H. (1981). Empty and filled interval discrimination by pigeons. Behaviour Analysis Letters, 1, 217-224.

MARICQ, A. V., RoBerTs, S., \& ChURCH, R. M. (1981). Methamphetamine and time estimation. Journal of Experimental Psychology: Animal Behavior Processes, 7, 18-30.

MECK, W. H. (1983). Selective adjustment of the speed of internal clock and memory processes. Journal of Experimental Psychology: Animal Behavior Processes, 9, 171-201.

MECK, W. H. (1986). Affinity for the dopamine D2 receptor predicts neuroleptic potency in decreasing the speed of an internal clock. Pharmacology, Biochemistry \& Behavior, 25, 1185-1189.

MECK, W. H. (1991). Modality-specific circadian rhythmicities influence mechanisms of attention and memory for interval timing. Learning \& Motivation, 22, 153-179.

MECK, W. H., \& CHURCH, R. M. (1982). Discrimination of intertrial intervals in cross-modal transfer of duration. Bulletin of the Psychonomic Society, 19, 234-236.

Meck, W. H., \& ChURCH, R. M. (1983). A mode control model of counting and timing processes. Journal of Experimental Psychology: Animal Behavior Processes, 9, 320-334.

Morrissey, G., Wogar, M. A., Bradshaw, C. M., \& Szabadi, E. (1993). Effect of lesions of the ascending 5-hydroxytryptaminergic pathways on timing behaviour investigated with an interval bisection task. Psychopharmacology, 112, 80-85.

Penton-Voak, I. S., Edwards, H., Percival, A., \& Weardon, J. H. (1996). Speeding up an internal clock in humans? Effects of click trains on subjective duration. Journal of Experimental Psychology: Animal Behavior Processes, 22, 307-320

RAMmSAYER, T. H., \& LIMA, S. D. (1991). Duration discrimination of filled and empty auditory intervals: Cognitive and perceptual factors. Perception \& Psychophysics, 50, 565-574.

Raslear, T. G., ShURTLEFF, D., \& Simmons, L. (1992). Intertrial-interval effects on sensitivity $\left(A^{\prime}\right)$ and response bias $\left(B^{\prime \prime}\right)$ in a temporal discrimination by rats. Journal of the Experimental Analysis of Behavior, 58, 527-535.

ROBERTS, S., \& HolDER, M. D. (1985). Effect of classical conditioning on an internal clock. Journal of Experimental Psychology: Animal Behavior Processes, 11, 194-214.

RoberTs, W. A., ChENG, K., \& COHEN, J. (1989). Timing light and tone signals in pigeons. Journal of Experimental Psychology: Animal Behavior Processes, 15, 23-35.

Roberts, W. A., MACUdA, T., \& Brodbeck, D. R. (1995). Memory for number of light flashes in the pigeon. Animal Learning \& Behavior, 23, 182-188.

SANTI, A., CoYle, J., CoPPA, R., \& Ross, L. (1998). The timing of auditory and visual signals by pigeons: Differential sensitivity to intertrial interval duration. Learning \& Motivation, 29, 345-365.

Santi, A., Stanford, L., \& Coyle, J. (1998). Pigeons' memory for event duration: Differences between visual and auditory signals. $A n$ imal Learning \& Behavior, 26, 163-171.

SPETCH, M. L., \& RUSAK, B. (1989). Pigeons' memory for event duration: Intertrial interval and delay effects. Animal Learning \& Behavior, 17, 147-156.

SPETCH, M. L., \& RusaK, B. (1992a). Temporal context effects in pigeons' memory for event duration. Learning \& Motivation, 23, 117 144.

SPETCH, M. L., \& RusaK, B. (1992b). Time present and time past. In W. K. Honig \& J. G. Fetterman (Eds.), Cognitive aspects of stimulus control (pp. 47-67). Hillsdale, NJ: Erlbaum.

SPETCH, M. L., \& WILKIE, D. M. (1983). Subjective shortening: A model of pigeons' memory for event duration. Journal of Experimental Psychology: Animal Behavior Processes, 9, 14-30.

STUBBS, A. (1968). The discrimination of stimulus duration by pigeons. Journal of the Experimental Analysis of Behavior, 11, 223-238.

STUBBS, A. (1976). Scaling of stimulus duration by pigeons. Journal of the Experimental Analysis of Behavior, 26, 15-25.

Wearden, J. H., Edwards, H., Fakhri, M., \& Percival, A. (1998). Why "sounds are judged longer than lights": Application of a model of the internal clock in humans. Quarterly Journal of Experimental Psychology, 51B, 97-120.

WILKIE, D. M. (1987). Stimulus intensity affects pigeons' timing behavior: Implications for an internal clock model. Animal Learning \& Behavior, 15, 35-39.

ZENTALl, T. R. (1997). Animal memory: The role of "instructions." Learning \& Motivation, 28, 280-308.

(Manuscript received August 19, 1998;

revision accepted for publication November 24, 1998.) 